\title{
Fast and Convenient Synthesis of Amine-Terminated Polylactide as a Macroinitiator for $\omega$-Benzyloxycarbonyl-L-Lysine- $\mathbf{N}$-Carboxyanhydrides
}

\author{
Mingjie Ju, Feirong Gong, Shujun Cheng, and Yun Gao \\ Key Laboratory for Ultrafine Materials of Ministry of Education, School of Materials Science and Engineering, \\ East China University of Science and Technology, Shanghai 200237, China \\ Correspondence should be addressed to Feirong Gong, gongfeirong@yahoo.com.cn
}

Received 26 May 2011; Accepted 29 June 2011

Academic Editor: Shanfeng Wang

Copyright ( $\odot 2011$ Mingjie Ju et al. This is an open access article distributed under the Creative Commons Attribution License, which permits unrestricted use, distribution, and reproduction in any medium, provided the original work is properly cited.

Amine-terminated poly (L-lactide) ( $\mathrm{NH}_{2}$-PLLA) with various chain lengths were successfully synthesized by sequential tertbutyl- $N$-(3-hydroxypropyl) carbamate initiated bulk ring-opening polymerization (ROP) of L-lactide (L-LA) in the presence of Stannous(II) 2-ethylhexanoate $\left(\mathrm{Sn}(\mathrm{Oct})_{2}\right)$ and deprotection of the $N$-tert-butoxycarbonyl (Boc) group at the end of the polymer chain. The polymers obtained were characterized by FT-IR, ${ }^{1} \mathrm{H}$ NMR, and GPC method. $\mathrm{NH}_{2}$-PLLA thus prepared was used to initiate the polymerization of $\omega$-benzyloxycarbonyl-L-lysine- $N$-carboxyanhydride (Lys (Z)-NCA), and the result confirmed the high nucleophilicity of the terminal amine group. This method was not only suitable for the preparation of low molecular weight $\mathrm{NH}_{2}$-PLLA, but also quite efficient in the synthesis of high molecular weight samples.

\section{Introduction}

During the last few years, aliphatic polyesters based on hydroxyalkanoic acid, such as polylactides (PLLA), polyglycolide (PGA), poly (caprolactone) (PCL), and their copolymers have become the most important biopolymers because of their biodegradability and good biocompatibility for pharmaceutical and biomedical applications. However, the scope of further application of PLLA is limited for the lacking of highly reactive groups as triggers of chemical reaction, and the surface of PLLA is very hydrophobic [1]. Chemical modification, especially end functionalization, is an important method to expand the applications area of these polymers [2]. The end-functionalized polymers are also important intermediates which can react at the end of the chain with other molecules containing reactive groups such as acid chlorides, sulfonyl chlorides, acid anhydrides, and activated esters for the synthesis of novel polymeric materials $[3,4]$. $\mathrm{NH}_{2}$-PLLA can be used to conjugate with lactose to form a new bioabsorbable material which shows high biodegradability and gives a microphase separation structure [1]. Especially, they were investigated as a macroinitiator for the ring-opening polymerization (ROP) of amino acid Ncarboxyanhydrides (NCAs) to prepare a block copolymer containing polypeptide segments which showed quite different properties from other polymers [5-14].

The synthesis of $\mathrm{NH}_{2}$-PLLA was based on a method first reported by Gotsche et al. in 1995 [5]. The main idea of his point was capping the hydroxyl end group of PLLA with BOC-L-Phe which containing a protective amino group using $\mathrm{N}, \mathrm{N}^{\prime}$-dicyclohexylcarbodiimide (DCC) as the condensing agent. However, conversion of the hydroxyl group into an N-protected amino acid ester with the acylation of DCC is always not sufficient, possibly because of the low reactivity of the terminal hydroxyl group and the steric hindrance of the huge polymer chain [7]. Fan et al. [8] synthesized a mixed acid anhydride of BOC-L-Phe and trimethylacetyl chloride (TMAC) to improve the reactivity of the coupling agent. The complete end capping of the end hydroxyl group of PLLA was achieved by reacting with the mixed acid anhydride under the existence of 4-(1-pyrrolidinyl) pyridine. Finally, the protective group was removed to form the free amino group at the chain end of PLLA. Caillol et al. [6] synthesized amino-functionalized PLLA through 


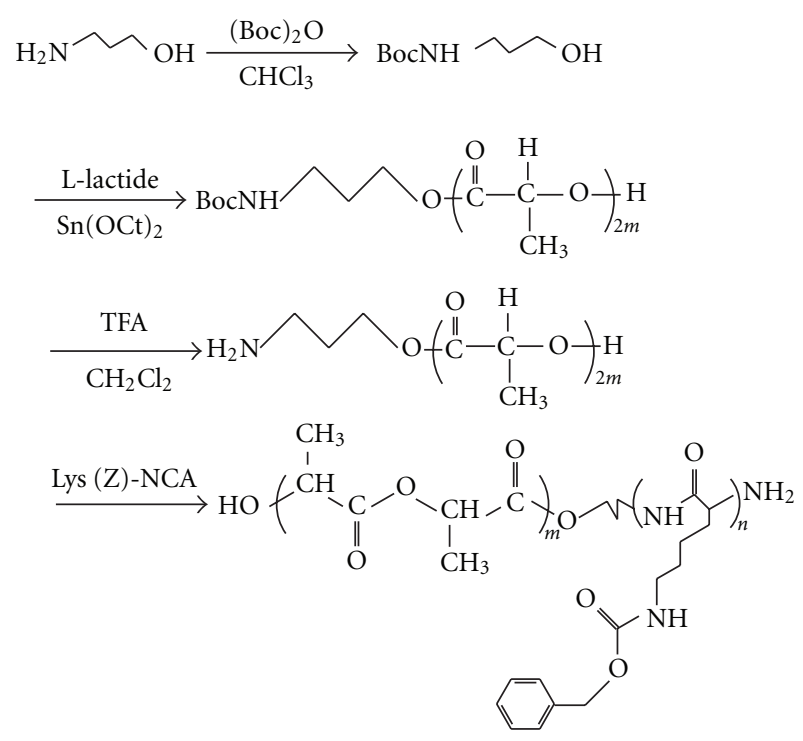

Figure 1: Synthesis of $\mathrm{NH}_{2}$-PLLA and PLLA- $b$-PZLys block copolymer.

ring-opening polymerization of L-LA initiated by zinc alkoxide that was obtained from the reaction between diethylzinc and tert-butyl- $\mathrm{N}$-(3-hydroxypropyl) carbamate. Lately, Ouchi et al. [1] synthesized $\mathrm{NH}_{2}$-PLLA through anionic ROP of L-LA in dry tetrahydrofuran using Boc-amino-OK as an initiator. But in our opinion, the initiators mentioned above were so sensitive to environmental factors such as humidity and oxygen that they were so difficult to handle and store.

Stannous(II) 2-ethylhexanoate $\left(\mathrm{Sn}(\mathrm{Oct})_{2}\right)$ is one of the most widely used compounds for catalyzing the ROP of various lactones and lactides [15-18]. Despite the fact that the mechanism and the initiating complex remain unclear, both mechanisms are thought to be alcohol initiated [1923 ], since the degree of polymerization is clearly dependent on the monomer-to-alcohol ratio [24], and the end groups of the polymers have hydroxyl functionalities. In the present research, we proposed a novel three-step method to achieve the complete end capping of PLLA with amine group by tertbutyl- $N$-(3-hydroxypropyl) carbamate initiated bulk ringopening polymerization of L-LA catalyzed by $\mathrm{Sn}(\mathrm{Oct})_{2}$. In order to control the molecular weight, alcohols have been widely used to initiate the bulk ring-opening polymerization of L-LA, but to our knowledge, the synthetic method of $\mathrm{NH}_{2}$-PLLA initiated by tert-butyl- $\mathrm{N}$-(3-hydroxypropyl) carbamate under the catalyzing of $\mathrm{Sn}(\mathrm{Oct})_{2}$ has not been published. The outline of the synthetic route is illustrated in Figure 1. At first, the amine group of 3-amino-1-propanol was protected by reaction with di-tert-butyl dicarbonate under the existence of triethylamine. Then, tert-butyl- $\mathrm{N}$-(3hydroxypropyl) carbamate synthesized above was used to initiate the polymerization of L-LA to prepared Boc-amino terminated PLLA (BocNH-PLLA). Finally, the Boc group at the chain end was removed by the treatment of trifluoroacetic acid. The synthesized $\mathrm{NH}_{2}$-PLLA $\left(\mathrm{NH}_{2}\right.$-PLLA) was used as a macroinitiator for the ROP of Lys (Z)-NCA to prepare the block copolymer of L-lactide and $\omega$-benzyloxycarbonyl-L-lysine (PLLA- $b$-PZLys).

\section{Experimental}

2.1. Materials. L-LA was purchased from PURAC and recrystallized twice from anhydrous ethyl acetate. Anhydrous trifluoroacetic acid (TFA), Sn(Oct) $)_{2}$ were from Sigma and distilled twice before use. Di-tert-butyldicarbonate, triphosgene, and $\omega$-benzyloxycarbonyl-L-lysine were purchased from GL biochemical of Shanghai and used as received. Lys (Z)-NCA was prepared according to the previously method [25]. The purity of the obtained NCA was checked by DSC analysis from the position and the shape of the melting process. The melting endotherm of Lys (Z)-NCA was about $100^{\circ} \mathrm{C}-101^{\circ} \mathrm{C}$ with a highly asymmetric peak, showing the absence of residual chloride. Other reagents were commercially available and used as received. All solvents were thoroughly dried and distilled before use.

\subsection{Synthesis}

2.2.1. Synthesis of Tert-Butyl-N-(3-Hydroxypropyl) Carbamate. 3-amino-1-propanol (1.52 g, $20 \mathrm{mmol})$ and triethyamine $(2.22 \mathrm{~g}, 22 \mathrm{mmol})$ were dissolved in chloroform $(50 \mathrm{~mL})$ in a flask equipped with a magnetic stirrer, and di-tertbutyldicarbonate $(4.8 \mathrm{~g}, 22 \mathrm{mmol})$ in chloroform $(20 \mathrm{~mL})$ was added dropwise to the solution in $1 \mathrm{~h}$ with continuous stirring. After reaction for another $1 \mathrm{~h}$, the concentrated solution was diluted with $5 \%$ potassium hydrogen sulfate aq. Soln. and extracted with ethyl acetate and dried over $\mathrm{MgSO}_{4}$. After filtration and evaporation of the solvent, purification of the compound was carried out by column chromatography on silica gel using ethyl acetate and hexane as eluent. The purity of tert-butyl- $\mathrm{N}$-(3-hydroxypropyl) carbamate obtained as colorless viscous oil was found to be over $98.7 \%$ by HPLC analysis. Yield: $86.2 \%$.

2.2.2. Preparation of BocNH-PLLA, PLLA 25. PLLA was synthesized by ROP of L-LA initiated by tert-butyl- $N$-(3-hydroxypropyl) carbamate and catalyzed by $\mathrm{Sn}(\mathrm{Oct})_{2}$. LLA (14.4 g, $100 \mathrm{mmol}$ ) and tert-butyl- $N$-(3-hydroxypropyl) carbamate $(700 \mathrm{mg}, 4 \mathrm{mmol}$ ) were weighted in a glove box and introduced in an oven-dried schlenk bottle, and $72 \mathrm{mg}$ of $\mathrm{Sn}(\mathrm{Oct})_{2}(0.5 \mathrm{of} \mathrm{L}-\mathrm{LA})$ was added as a $0.02 \mathrm{~g} / \mathrm{mL}$ solution in dry dichloromethane. After vacuumized and purged with $\mathrm{Ar}$ three times, the bottle was degassed under a high vacuum for $2 \mathrm{~h}$ to remove the residue dichloromethane. The bottle was then flame-sealed and immersed in a $130^{\circ} \mathrm{C}$ oil bath for $6 \mathrm{~h}$. The obtained white solid was dissolved in dichloromethane, and the catalyst $\mathrm{Sn}(\mathrm{Oct})_{2}$ was removed by precipitating the polymer solution in a large amount of chilled methanol, filtered and dried in vacuum at room temperature. The polymer was recovered over $85 \%$ yield with a stannous content less than $20 \mathrm{ppm}$.

2.2.3. Synthesis of Amine-Terminated PLLA. $1 \mathrm{~g}$ of PLLA was introduced in a flask which has been dried, purged with $\mathrm{Ar}$ 


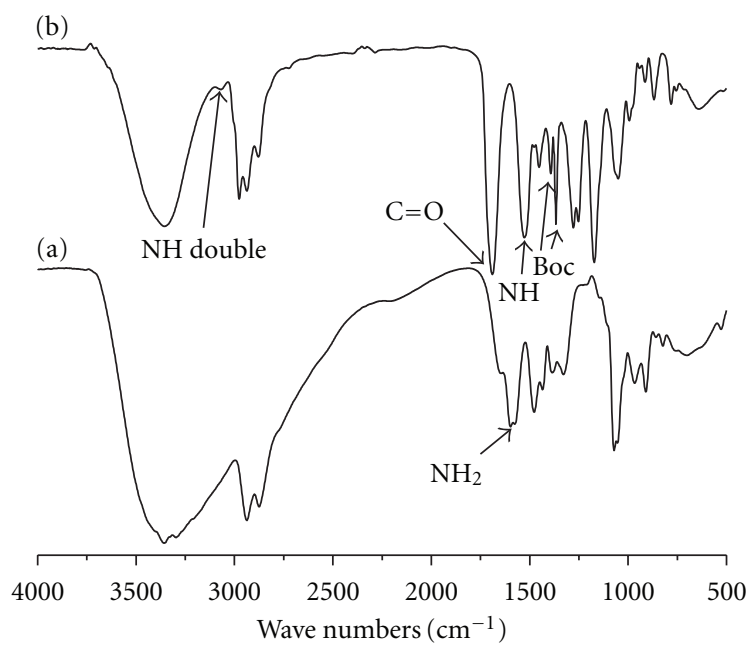

FIGURE 2: FT-IR spectra of 3-amino-1-propanol (a) and tert-butyl$N$-(3-hydroxypropyl) carbamate (b).

and vacuumized several times. Freshly distilled methylene chloride $(12 \mathrm{~mL})$ was added, followed by a large excess of anhydrous trifluoroacetic acid $(6 \mathrm{~mL})$. The solution was stirred at room temperature for $1 \mathrm{~h}$, after which time all solvents were evaporated, the polymer was redissolved in dichloromethane and washed with aqueous $\mathrm{NaHCO}_{3}(5 \%)$ and water and finally dried over $\mathrm{MgSO}_{4}$. After filtration, the solution was precipitated in chilled methanol and dried in a vacuum at room temperature. The polymer was recovered over $80 \%$ yield.

2.2.4. Synthesis of PLLA-b-PZLys Block Copolymer. $2 \mathrm{~g}$ $(6.5 \mathrm{mmol})$ or $5 \mathrm{~g}(16.3 \mathrm{mmol})$ of Lys (Z)-NCA was dissolved in $50 \mathrm{~mL}$ of $\mathrm{CH}_{2} \mathrm{Cl}_{2}$. The resultant solution was added to a solution of $\mathrm{NH}_{2}-\mathrm{PLLA}_{25}\left(1 \mathrm{~g}, 0.27 \mathrm{mmol}\right.$ ) in $15 \mathrm{~mL} \mathrm{CH}_{2} \mathrm{Cl}_{2}$. The reaction mixture was stirred under an inert atmosphere for $24 \mathrm{~h}$ at room temperature. The viscous solution obtained was poured into a large quantity of chilled diethyl ether, followed by filtration and drying under reduced pressure to give a white powder over $90 \%$ yield.

2.2.5. In Vivo Tissue Responses. Boc-PLLA ( $\left.\mathrm{DP}_{\mathrm{LA}}=100\right)$, $\mathrm{NH}_{2}$-PLLA $\left(\mathrm{DP}_{\mathrm{LA}}=100\right)$, and PLLA- $b$-PZLys $\left(\mathrm{DP}_{\mathrm{LA}}=25\right.$, $\left.\mathrm{DP}_{\text {ZLys }}=24\right)$ were dissolved in $\mathrm{CH}_{2} \mathrm{Cl}_{2}$ at a concentration of $10 \%(\mathrm{w} / \mathrm{v})$ in the watch glass. Polymer films were obtained by evaporating the solution under room temperature and dried in vacuum for 3 days. Nude rats weighing 200-250 g were implanted with the polymer films $(n=4$ for each polymer) in legs. Animals with polymer films were allowed to survive 28 days after implantation and then terminated. The surgical wounds were reopened, and the leg musculature was removed with the polymer remnant and fixed in $10 \%$ formalin for histological analysis. Specimens were prepared for H-E staining analysis.

2.3. Measurements. ${ }^{1} \mathrm{H}-\mathrm{NMR}$ spectra were recorded at room temperature on a Bruker DRX-500 using $\mathrm{CDCl}_{3}$ as the solvent. Gel permeation chromatography (GPC) was carried

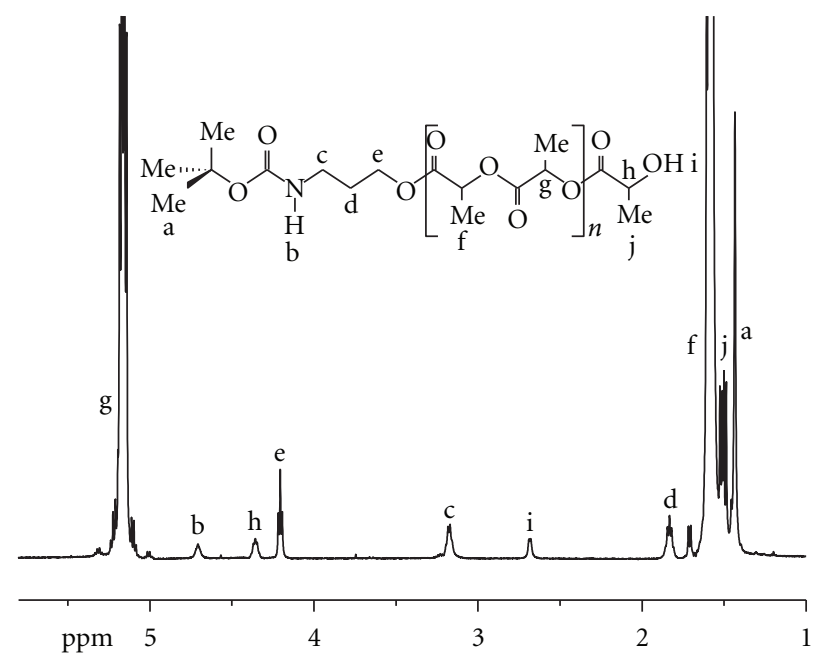

Figure 3: ${ }^{1} \mathrm{NMR}$ spectra of BocNH-PLLA in $\mathrm{CDCl}_{3}$.

out on a Waters HPLC system equipped with a Model 2690D separation module, a Model 2410 refractive index detector, and Shodex columns (K802.5, K803, and 805). Chloroform was used as eluent at the flow rate of $1.0 \mathrm{~mL} / \mathrm{min}$. Calibration was fulfilled with narrow-molar-mass distributed polystyrene standards. The infrared spectral analysis of the samples was performed on a FT-IR spectrophotometer (Nicolet Magna-IR550).

\section{Result and Discussion}

The general synthetic routes for the preparation of tertbutyl- $N$-(3-hydroxypropyl) carbamate, BocNH-PLLA, $\mathrm{NH}_{2}$ PLLA, and PLLA- $b$-PZLys were shown in Figure 1.

\subsection{Synthesis of Tert-Butyl-N-(3-Hydroxypropyl) Carbamate.} Boc was chosen as the protective group for amine group of 3-amino-1-propanol because of its stability under the designed temperature of polymerization of L-LA and it can be easily removed under mild conditions. Tert-butyl- $\mathrm{N}$-(3hydroxypropyl) carbamate was obtained from the reaction of 3-amino-1-propanol and di-tert-butyldicarbonate at room temperature under the existence of triethylamine. The complete protection of the amine group was confirmed by IR spectra (Figure 2). The absorption peak at $1649.0 \mathrm{~cm}^{-1}$ assigned to primary amine was completely disappeared in tert-butyl- $N$-(3-hydroxypropyl) carbamate, and the peaks at $1527.0 \mathrm{~cm}^{-1}\left(\nu_{\mathrm{CO}-\mathrm{NH}}\right)$ and $1689.6 \mathrm{~cm}^{-1}\left(\nu_{\mathrm{CO}}\right)$ were attributed to second amide, indicating the successive protection of amine group by $t$-butoxycarbonyl. The peaks at $1366.7 \mathrm{~cm}^{-1}$ and $1392.8 \mathrm{~cm}^{-1}$ belonged to the Boc group were also characteristic of the formation of tert-butyl- $\mathrm{N}$-(3-hydroxypropyl) carbamate.

3.2. Synthesis of $\mathrm{NH}_{2}-\mathrm{PLLA}$. Amino-functionalized PLLA was synthesized through ROP of L-LA with tert-butyl- $N$ (3-hydroxypropyl) carbamate. The bulk polymerization can be easily carried out at $130^{\circ} \mathrm{C}$ because of the stabilization of 


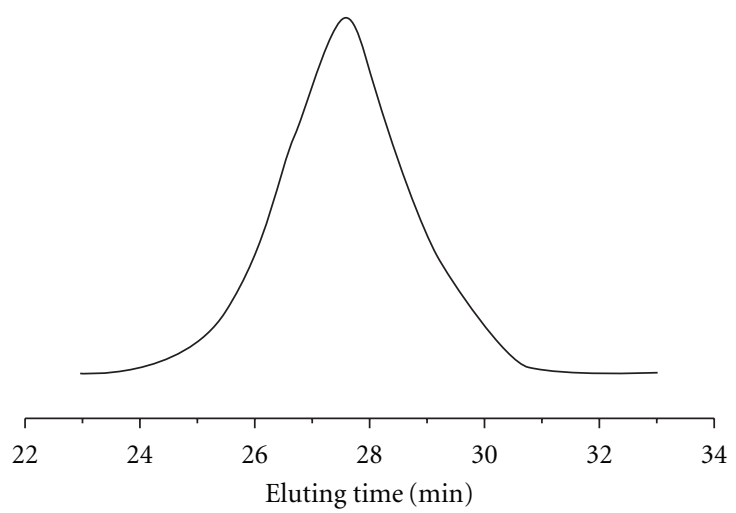

(a)

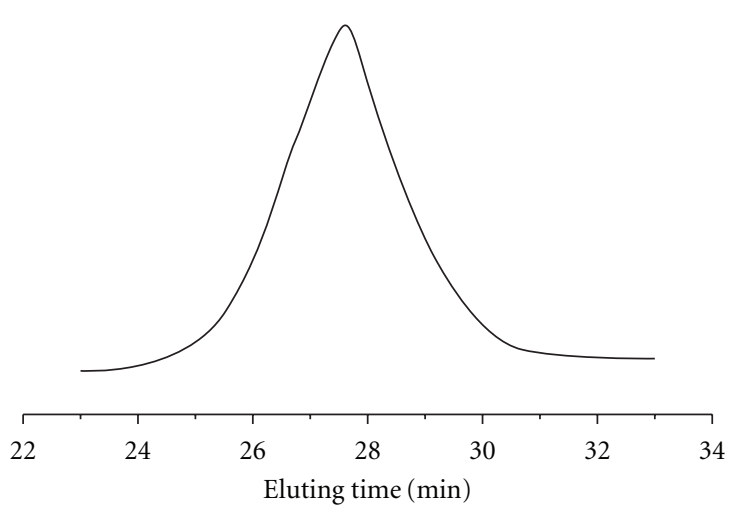

(b)

Figure 4: GPC curves of BocNH-PLLA (a) and $\mathrm{NH}_{2}$-PLLA (b).

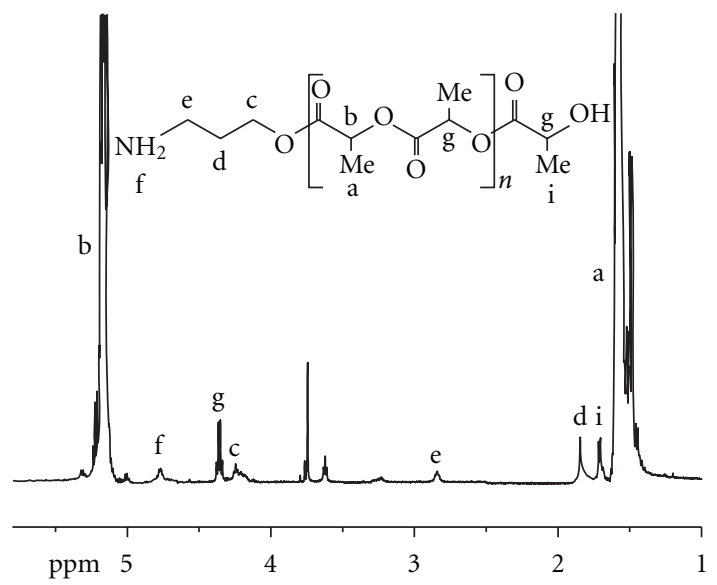

Figure 5: ${ }^{1} \mathrm{H}$ NMR spectra of $\mathrm{NH}_{2}$-PLLA in $\mathrm{CDCl}_{3}$.

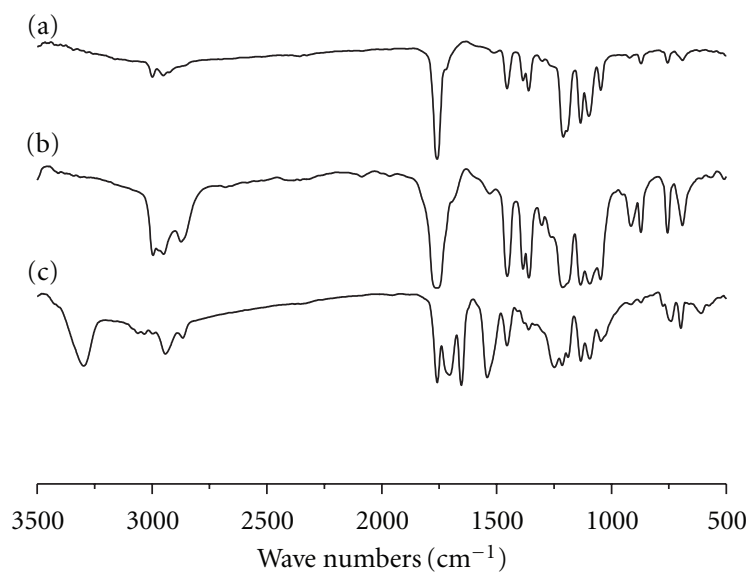

Figure 6: FT-IR spectra of BocNH-PLLA (a), $\mathrm{NH}_{2}$-PLLA (b), and PLLA- $b$-PZLys (c).

Boc group under this temperature in $12 \mathrm{~h}$ with high yields in recovered polymer between $85 \%$ and $98 \%$. In this study, the polymerization of L-LA was carried out under rigorously anhydrous conditions to avoid any initiation of water, which will lead to a mixture of carboxyl acid terminated PLLA

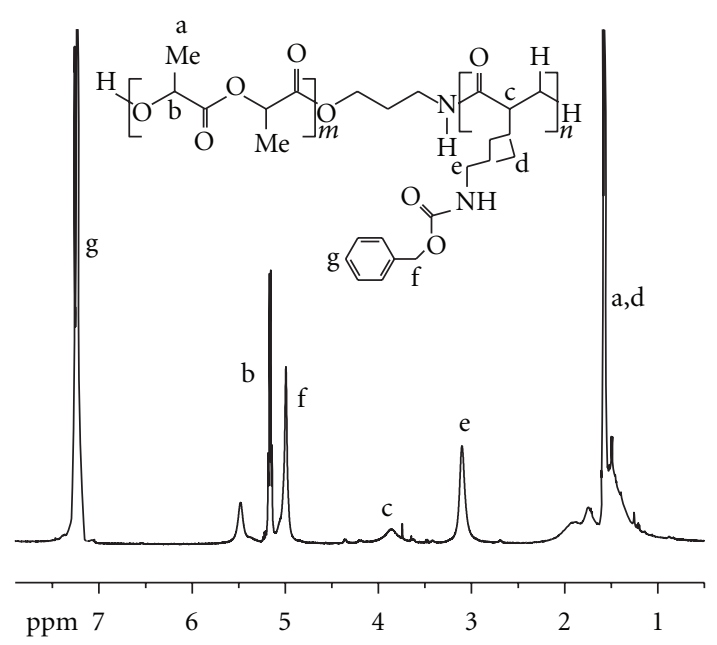

Figure 7: ${ }^{1} \mathrm{H}$ NMR spectra of the block copolymer of PLLA- $b$ PZLys.

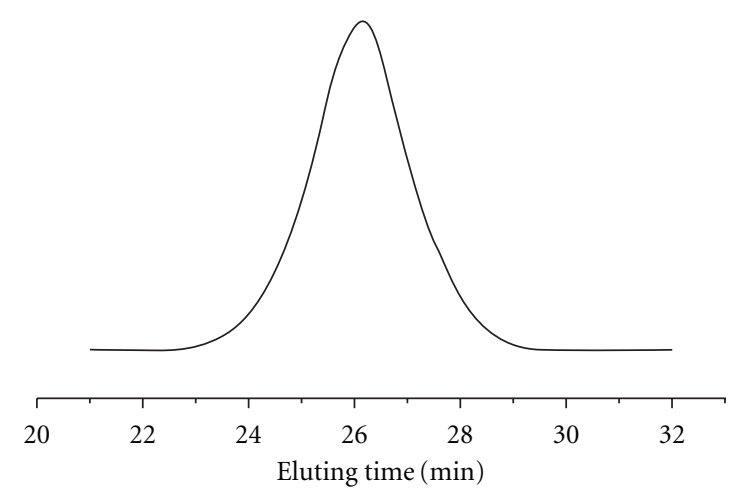

FIGURE 8: GPC trace of the block copolymer of PLLA- $b$-PZLys.

and BocNH-PLLA. The degree of polymerization of BocNHPLLA was found to be easily controlled by changing the feed molar ratio of L-LA to tert-butyl- $N$-(3-hydroxypropyl) carbamate. The characteristics of the synthesized polymers are reported in Table 1. 


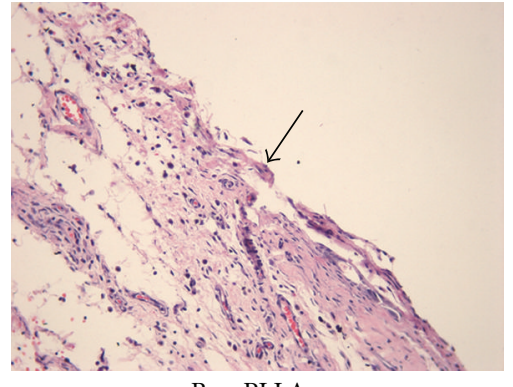

Boc-PLLA

(a)

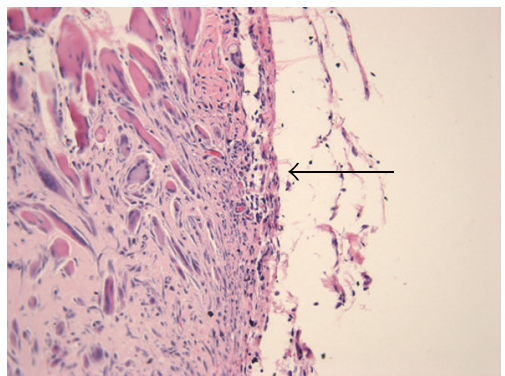

$\mathrm{NH}_{2}$-PLLA

(b)

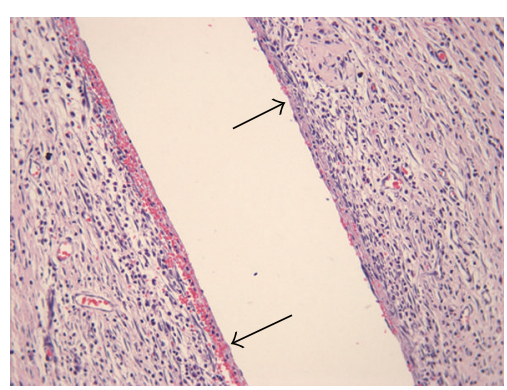

PLLA- $b$-PZLys

(c)

FIGURE 9: In vivo biocompatibility of the polymer films (interface surfaces are denoted by arrows).

TABLE 1: Molecular weight characterization of BocNH-PLLA homopolymers.

\begin{tabular}{lccccccc}
\hline Sample & $M_{0} / I_{0}(\mathrm{~mol})$ & $\mathrm{Mn}^{\mathrm{a}}$ & $\mathrm{Mn}^{\mathrm{b}}$ & $\mathrm{Mn}^{\mathrm{c}}$ & $\mathrm{PDI}$ & $\mathrm{Mn}^{\mathrm{d}}$ & $\mathrm{Mn}^{\mathrm{b}} / \mathrm{Mn}^{\mathrm{d}}$ \\
\hline PLLA $_{10}$ & 10 & 1440 & 1544 & 2680 & 1.21 & 1527 & 361 \\
PLLA $_{25}$ & 25 & 3600 & 3487 & 6423 & 1.24 & 0.95 \\
PLLA $_{50}$ & 50 & 7200 & 7663 & 13848 & 1.52 & 7893 & 0.97 \\
PLLA $_{100}$ & 100 & 14400 & 15295 & 28657 & 1.48 & 16334 & 0.94 \\
PLLA $_{150}$ & 150 & 21600 & 22927 & 39569 & 1.46 & 22554 \\
PLLA $_{200}$ & 200 & 28000 & 33295 & 55436 & 1.61 & 31599 & 1.02 \\
\hline
\end{tabular}

${ }^{a}$ Calculated from the free ratio. ${ }^{\mathrm{b}}$ Calculated from the ${ }^{1} \mathrm{H}$ NMR (see Figure 2). ${ }^{\mathrm{c}}$ Obtained from GPC based on the PS calibration. ${ }^{\mathrm{d}}$ Corrected GPC result, $\mathrm{Mn}^{\mathrm{c}} \times 0.57$.

The functionality of the end group of the polymer was determined by comparing the molecular weight obtained from GPC and that determined by ${ }^{1} \mathrm{H}$ NMR [6] using the signals of a, c, or e attributed to the end group and that of lactide units $\mathrm{g}$ or $\mathrm{f}$ (Figure 3 ). In all cases, the functionality was found close to 1 , which means that all polymer chains were capped with BocNH groups. The GPC trace of the resulted polymer (Figure 4(a)) is a single peak, and the molecular weight distribution of the product is narrow, showing that only one type of polymer corresponding to the expecting end group.

The next step removal of the Boc group of the terminal residue from the obtained polymer was realized by treatment in the mixed solvent of TFA and $\mathrm{CH}_{2} \mathrm{Cl}_{2}$ at room temperature for 1 hour. This reaction deprotected all primary amine functions at the end of the polymer, without lowering the molecular weight, as shown by the GPC trace (Figure 4(b)). This was also confirmed by ${ }^{1} \mathrm{H}$ NMR (Figure 5) with the complete disappearance of methyl peak at $1.43 \mathrm{ppm}$ corresponding to the terminal Boc group. The signal of $-\mathrm{CH}_{2}-\mathrm{N}$ shifted from 3.16 to $2.75 \mathrm{ppm}$. The ratio between this peak and that of lactide units ( $a$ and $b$ ) remained also constant after the deprotection, showing the degree of polymerization not changed.

3.3. Block Copolymerization. It is well known that primary amines, being more nucleophilic than basic, can be used to initiate the ROP of NCAs to prepare polypeptide containing block copolymers. Among all polypeptides, poly (L-lysine) (PLL) is unique due to its hydrophilicity and functional side $\mathrm{NH}_{2}$ groups which can help to improve the affinity to proteins and cells, or to ionically combine with drugs, antibodies or DNAs, and thus may lead to breakthrough in fields of targeting drug delivery and gene delivery [26, 27]. Therefore, in order to test the reactivity of the amineterminated polymer prepared above, $\mathrm{NH}_{2}$-PLLA was used as a macroinitiator for the ROP of lys (Z)-NCA. FT-IR spectra of BocNH-PLLA, $\mathrm{NH}_{2}$-PLLA, and PLLA- $b$-PZLys were illustrated in Figure 6 . The absorption at $1758 \mathrm{~cm}^{-1}$ belong to the carbonyl group, $1951 \mathrm{~cm}^{-1}$ to methyl, and 1046 and $1098 \mathrm{~cm}^{-1}$ to $\mathrm{C}-\mathrm{O}-\mathrm{C}$ bond. In the spectrum of the block copolymer, two amide I bands at $1653 \mathrm{~cm}^{-1}$ and $1704 \mathrm{~cm}^{-1}$ were observed, most likely for the main chain amide linkage and the side amide group, respectively. The amide II band was also observed at $1540 \mathrm{~cm}^{-1}$.

Figure 7 illustrates the ${ }^{1} \mathrm{H}$ NMR spectra of the block copolymer. Besides the signals of PLLA, new peaks at about $7.23,4.96,3.85$, and $3.03 \mathrm{ppm}$ corresponding to the lysine residue appeared. From the integral ratio of lactide unit to lysine unit, the average degree of polymerization (DP) of the polypeptide block can be easily calculated to be 21 and 53 , which is very close to the feed molar ratio of NCA monomer to the macroinitiator, confirming the high initiation reactivity of $\mathrm{NH}_{2}$-PLLA. The GPC trace of the resulting copolymer (Figure 8) showed a unimodal shape. This further indicated complete amine-end-capping of PLLA, and the copolymerization was completed successfully, and there was no homopolymer in the copolymer.

3.4. In Vivo Tissue Responses. The in vivo biocompatibility of Boc-PLLA, $\mathrm{NH}_{2}$-PLLA, and PLLA- $b$-PZLys was evaluated via implantation of the polymer films in rats (Figure 9). 
The polymeric implants and surrounding tissues were collected at day 28. Despite the difference in molecular weight and structures, there was no significant difference in inflammatory reactions between the polymers as assessed by fibrotic band thickness and lymphocytes infiltration, as shown in Figure 9. The three polymer films caused same fibrotic band thickness and the surrounding tissues showed an abundant perivascular infiltration of lymphocytes, which was most probably caused by the degradation of the polymer films.

\section{Conclusion}

Compared to the methods that have been published, a novel, very simple, and highly efficient approach for the synthesis of amine-terminated polylactide (may also be used for other kinds of polylactones and polylactides) with various chain lengths based on tert-butyl- $N$-(3-hydroxypropyl) carbamate initiated bulk ring-opening polymerization has been developed and shown to be successful. The deprotection of the Boc group can be easily carried out under mild condition without breaking up of the polymer chain. This method was confirmed not only suitable for the preparation of low molecular weight $\mathrm{NH}_{2}$-PLLA, but also quite efficient in the synthesis of high molecular weight samples.

\section{Acknowledgment}

The authors would like to thank the National Basic Research Program of China (no. 81000105) for the financial support to this work.

\section{References}

[1] T. Ouchi, T. Uchida, H. Arimura, and Y. Ohya, "Synthesis of poly(L-lactide) end-capped with lactose residue," Biomacromolecules, vol. 4, no. 3, pp. 477-480, 2003.

[2] F.-Z. Lu, X.-Y. Xiong, Z.-C. Li, F.-S. Du, B.-Y. Zhang, and F.-M. Li, "A convenient method for the synthesis of amineterminated poly(ethylene oxide) and poly(E-caprolactone)," Bioconjugate Chemistry, vol. 13, no. 5, pp. 1159-1162, 2002.

[3] P.-R. Ashton, S.-E. Boyd, C.-L. Brown et al., "Synthesis of glycodendrimers by modification of poly(propylene imine) dendrimers," Chemistry, vol. 3, no. 6, pp. 974-984, 1997.

[4] P. Degee, P. Dubois, R. Jerome, and P. Teyssie, "Macromolecular engineering of polylactones and polylactides. 9. Synthesis, characterization, and application of $\omega$-primary amine poly (E-caprolactone)," Macromolecules, vol. 25, no. 17, pp. 42424248, 1992.

[5] M. Gotsche, H. Keul, and H. Höcke, "Amino-termined poly (L-lactide)s as initiators for the polymerization of $\mathrm{N}$ carboxyanhydrides: synthesis of poly(L-lactide)-block-poly $(\alpha$ amino acid)s," Macromolecular Chemistry and Physics, vol. 196, no. 12, pp. 3891-3903, 1995.

[6] S. Caillol, S. Lecommandoux, A.-F. Mingotaud et al., "Synthesis and self-assembly properties of peptide-polylactide block copolymers," Macromolecules, vol. 36, no. 4, pp. 1118-1124, 2003.

[7] N. Kang and J.-C. Leroux, "Triblock and star-block copolymers of $\mathrm{N}$-(2-hydroxypropyl)methacrylamide or $\mathrm{N}$-vinyl-2pyrrolidone and d,l-lactide: synthesis and self-assembling properties in water," Polymer, vol. 45, no. 26, pp. 8967-8980, 2004.

[8] Y. F. Fan, G. Chen, J. Tanaka, and T. Tateishi, "L-Phe endcapped poly(L-lactide) as macroinitiator for the synthesis of poly(L-lactide)-b-poly(L-lysine) block copolymer," Biomacromolecules, vol. 6, no. 6, pp. 3051-3056, 2005.

[9] M.-L Yuan and X.-M Deng, "Synthesis and characterization of poly(ethylene glycol)-block-poly(amino acid) copolymer," European Polymer Journal, vol. 37, no. 9, pp. 1907-1912, 2001.

[10] Z.-G Yang, J. Yuan, and S.-Y Cheng, "Self-assembling of biocompatible BAB amphiphilic triblock copolymers PLL(Z)PEG-PLL(Z) in aqueous medium," European Polymer Journal, vol. 41, no. 2, pp. 267-274, 2005.

[11] H.-Y. Tian, C. Deng, H. Lin et al., "Biodegradable cationic PEG-PEI-PBLG hyperbranched block copolymer: synthesis and micelle characterization," Biomaterials, vol. 26, no. 20, pp. 4209-4217, 2005.

[12] C. Deng, H. Tian, P. Zhang, J. Sun, X.-S. Chen, and X.-B. Jing, "Synthesis and characterization of RGD peptide grafted poly(ethylene glycol)- $b$-poly(L-lactide)- $b$-poly(Lglutamic acid) triblock copolymer," Biomacromolecules, vol. 7, no. 2, pp. 590-596, 2006.

[13] C. Deng, X. Chen, H. Yu, J. Sun, T. Lu, and X. Jing, "A biodegradable triblock copolymer poly(ethylene glycol)- $b$-poly(llactide)-b-poly(l-lysine): synthesis, self-assembly, and RGD peptide modification," Polymer, vol. 48, no. 1, pp. 139-149, 2007.

[14] J. Rao, Z. Luo, Z. Ge, H. Liu, and S. Liu, "'Schizophrenic' micellization associated with coil-to-helix transitions based on polypeptide hybrid double hydrophilic rod-coil diblock copolymer," Biomacromolecules, vol. 8, no. 12, pp. 3871-3878, 2007.

[15] D.-K. Gilding and A. M. Reed, "Biodegradable polymers for use in surgery-poly(ethylene oxide) poly(ethylene terephthalate) (PEO/PET) copolymers: 1," Polymer, vol. 20, no. 12, pp. 1454-1458, 1979.

[16] D.-W. Grijpma, G.-J. Zondervan, and A.-J. Pennings, "High molecular weight copolymers of L-lactide and $\varepsilon$-caprolactone as biodegradable elastomeric implant materials," Polymer Bulletin, vol. 25, no. 3, pp. 327-333, 1991.

[17] H.-R. Kricheldorf and J. Meier-Haack, "Polylactones, 22 ABA triblock copolymers of L-lactide and poly (ethylene glycol)," Macromolecular Chemistry and Physics, vol. 194, no. 2, pp. 715-725, 1993.

[18] A.-C. Albertsson and M. Gruvegård, "Degradable high-molecular-weight random copolymers, based on $\varepsilon$-caprolactone and 1,5-dioxepan-2-one, with non-crystallizable units inserted in the crystalline structure," Polymer, vol. 36, no. 5, pp. 10091016, 1995.

[19] Y.-J. Du, P.-J. Lemstra, A.-J. Nijenhuis, A.-M. Van Aert, and C. Bastiaansen, "ABA type copolymers of lactide with poly(ethylene glycol). Kinetic, mechanistic, and model studies," Macromolecules, vol. 28, no. 7, pp. 2124-2132, 1995.

[20] A. Schindler, Y.-M. Hibionada, and C.-G. Pitt, "Aliphatic polyesters. III. Molecular weight and molecular weight distribution in alcohol-initiated polymerizations of $\mathcal{E}$ caprolactone," Journal of polymer science: Part A, vol. 20, no. 2, pp. 319-326, 1982.

[21] X.-C. Zhang, D.-A. Macdonald, M.-F.-A. Goosen, and K.-B. Mcauley, "Mechanism of lactide polymerization in the presence of stannous octoate: the effect of hydroxy and carboxylic acid substances," Journal of Polymer Science: Part A, vol. 32, no. 15, pp. 2965-2970, 1994. 
[22] A.-J. Nijenhuis, D.-W. Grijpma, and A.-J. Pennings, "Lewis acid catalyzed polymerization of L-lactide. Kinetics and mechanism of the bulk polymerization," Macromolecules, vol. 25, no. 24, pp. 6419-6424, 1992.

[23] M. Ryner, K. Stridsberg, A.-C. Albertsson, H. Von Schenck, and M. Svensson, "Mechanism of ring-opening polymerization of 1,5-dioxepan-2-one and L-lactide with stannous 2ethylhexanoate. A theoretical study," Macromolecules, vol. 34, no. 12 , pp. 3877-3881, 2001.

[24] A. Kowalski, A. Duda, and S. Penczek, "Mechanism of cyclic ester polymerization initiated with tin(II) octoate. 2. 1 macromolecules fitted with tin(II) alkoxide species observed directly in MALDI-TOF spectra," Macromolecules, vol. 33, no. 3, pp. 689-695, 2000.

[25] D. S. Porche, M. Moore, and J. L. Bowles, "An unconventional method for the prepration of NCAs," Synthetic Communications, vol. 29, pp. 843-852, 1999.

[26] Y. Kakizawa, A. Harada, and K. Kataoka, "Glutathionesensitive stabilization of block copolymer micelles composed of antisense DNA and thiolated poly(ethylene glycol)-blockpoly(L-lysine): a potential carrier for systemic delivery of antisense DNA," Biomacromolecules, vol. 2, no. 2, pp. 491-497, 2001.

[27] S. Park and K. E. Healy, "Nanoparticulate DNA packaging using terpolymers of poly (lysine-g-(lactide- $b$-ethylene glycol))," Bioconjugate Chemistry, vol. 14, no. 2, pp. 311-319, 2003. 

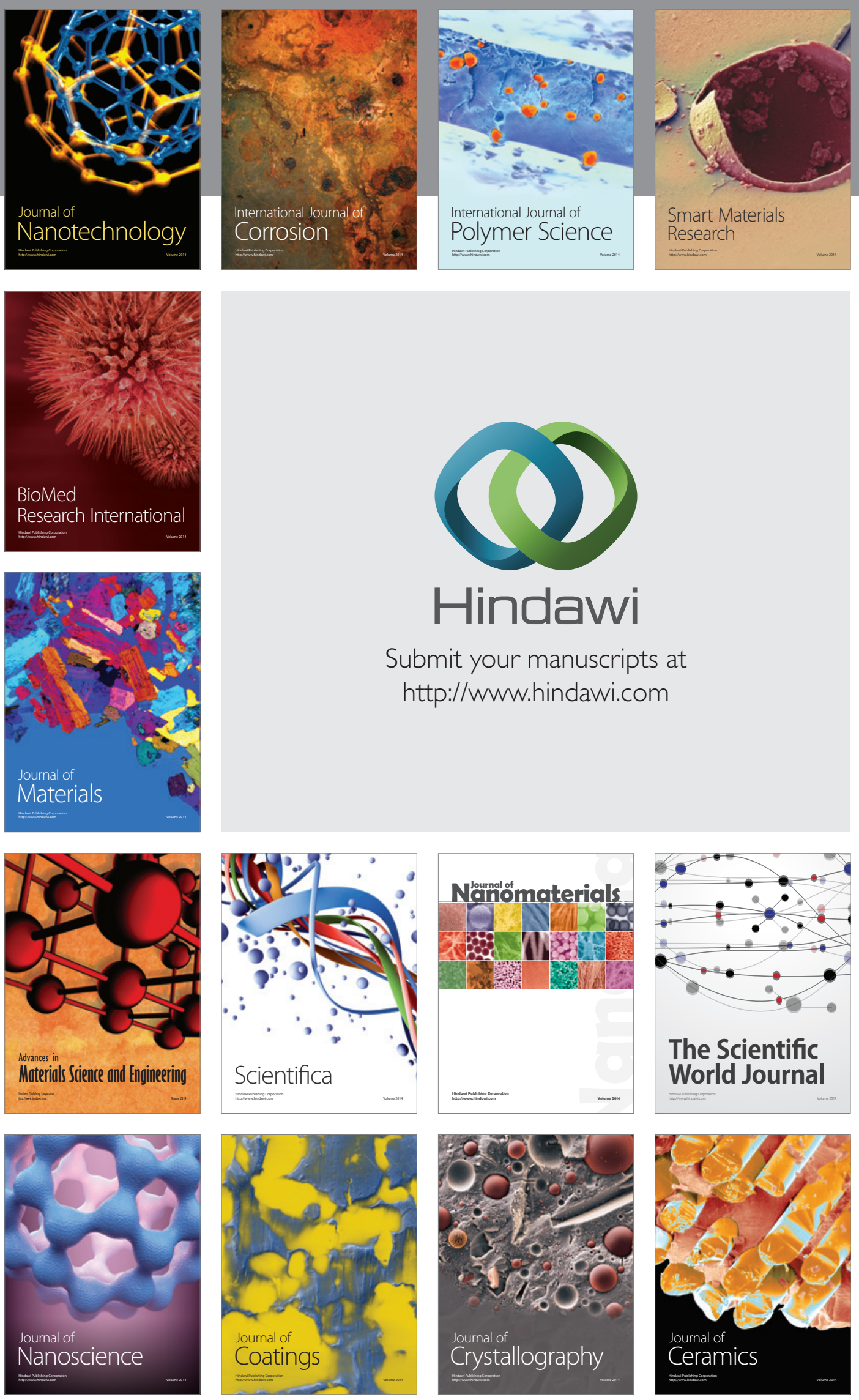

The Scientific World Journal

Submit your manuscripts at

http://www.hindawi.com

\section{World Journal}

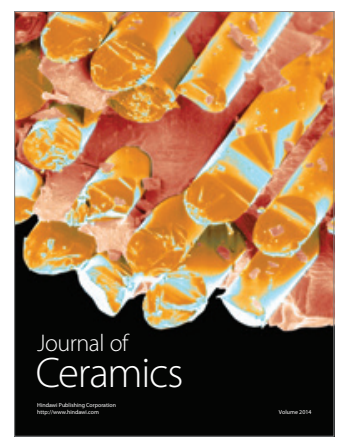

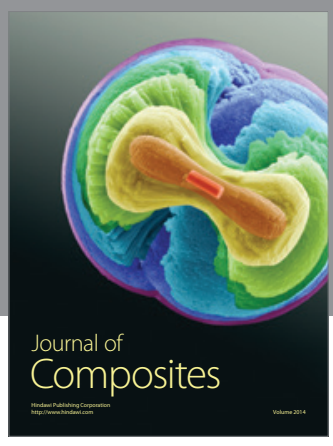
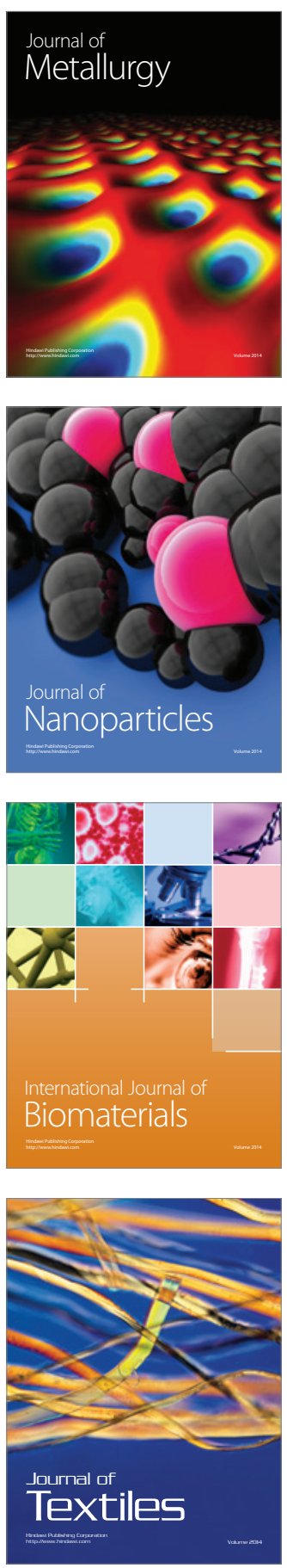